\title{
Fabrication of NiO/MWNTs modified Screen Printed Electrodes for the determination of norepinephrine in the biological fluids
}

\author{
Ji Ma ${ }^{1, \#}$, Ying Xiong ${ }^{2, \#}$, Yuting Wang ${ }^{4}$, Ding Hong ${ }^{4}$, Meng Zhao ${ }^{3, *}$ \\ ${ }^{1}$ Department of Endocrinogy, Xiangyang Central Hospital, Affiliated Hospital of Hubei University of \\ Arts and Science, Xiangyang 441053, China. \\ ${ }^{2}$ Department of Pharmacy, Wuhan No.5 Hospital, Wuhan 430050, China. \\ ${ }^{3}$ Department of psychology, Wuhan Wudong Hospital (Wuhan Second Mental Hospital), Wuhan \\ 430084, China. \\ ${ }^{4}$ Department of Pharmacy, Wuhan University, Wuhan 430072, China. \\ \#These authors equally contributed to this work.

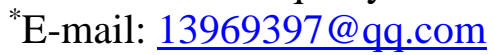

doi: $10.20964 / 2020.09 .42$

Received: 28 April 2020 / Accepted: 22 June 2020 / Published: 10 August 2020

\begin{abstract}
Depression was a most common human disorder disease because of insufficient neurotransmitter supply such as norepinephrine (NE). Hence, the accuracy measurement for NE levels in biological fluids including cerebrospinal fluid, brain tissue or blood sample was essential and important to diagnosis some psychiatric and neurological disorders diseases. However, a novel layered-designed composite sensor of $\mathrm{NiO} / \mathrm{MWNTs} / \mathrm{SPE}$ was fabricated and developed to detect brain $\mathrm{NE}$ level in depression mice model. The developed SPE exhibited good electrocatalytic activity response to the oxidation of NE during the brain tissue sample detection. The oxidative peak current was linearly related with the NE concentration from the range of $0.75 \mu \mathrm{M}$ to $30.0 \mu \mathrm{M}$, measured by square wave voltammetry (SWV) under the optimal conditions. The detection limit for NE was calculated as $0.05 \mu \mathrm{M}(\mathrm{S} / \mathrm{N})$. The newly method presented excellent selectivity and sensitivity for the NE detection in real brain samples with good linear equation compared to the HPLC method, which was benefit for the fast diagnosis of neurological disorders diseases. In conclusion, this experiment demonstrated that the developed sensor was attractive for NE detection in the clinical future diagnosis of mental disease.
\end{abstract}

Keywords: NiO/MWNTs, norepinephrine, screen printed electrode, real brain sample

\section{$\underline{\text { FULL TEXT }}$}

(C) 2020 The Authors. Published by ESG (www.electrochemsci.org). This article is an open access article distributed under the terms and conditions of the Creative Commons Attribution license (http://creativecommons.org/licenses/by/4.0/). 